\title{
Cultural Absence in China's Tertiary EFL Teaching
}

\author{
Li Huijie, Meng Xuemei \\ Harbin Institute of Technology, China
}

\begin{abstract}
Effective intercultural communication involves the students' awareness of not only the culture of the target language, but also of their own culture, on the basis of which their sensitivity to cultural differences, an important part of communicative competence, can be built up. However, while Chinese students are concentrating on learning the culture of Anglo-American English in the EFL classroom, the education of students' own culture is neglected. The absence of Chinese traditional culture in the EFL classroom has become a serious problem in China's tertiary English teaching. This paper assumes that the serious phenomenon might be accounted for from three aspects. In the first place, the present English textbooks seldom include materials introducing Chinese culture. Secondly, Chinese universities pay less attention to providing forum for students to exchange opinions on traditional culture and history; and thirdly, the learning resources about Chinese culture are poorly accessible. The paper also comes up with some solutions to this phenomenon in the ways of revising textbooks, giving optional courses related to cultural comparison, and making use of web resources.
\end{abstract}

\section{Introduction}

Language and culture are inseparable. Language usage and cultural knowledge are both integral for English as a Foreign Language (EFL) learning and teaching. Here I make the point that not only the cultural knowledge of the target language plays roles in EFL teaching, but also that of the native language should be involved. After all, English language serves as a medium in the communication between two cultures, and it is the cultural information gap that drives the ongoing of the communication [3].

The overwhelming globalization is inexorable; however, its dark side is gaining people's attention as well [7]. The phrase "Cultural absence" originates from a belief that "globalization results in cultural loss or absence." I borrow this phrase to disclose a phenomenon that Chinese college students do poorly in communication with westerners partly because they are unable to give a clear explanation to their tradition, which is what most foreigners are interested in.

Many years ago, a satiric essay impressed me a lot: A foreigner was interested in Chinese food.
During his visit to a university in China, he asked ten students one by one "What do you have for breakfast" to make a survey. To his surprise, all the students gave him the same answer "bread". Later on, he found out the reason that the Chinese students did not know how to say "mantou (steam bread)" "youtiao (fried flour chips)" and "zhou (rice porridge)" in English, the only English word concerning food they had learned was "bread".

Similarly, I once asked 10 colleagues of mine to imagine the following situation and answer some questions. The questionnaire I devised is as follows: A is a college student from the U.S. and B is also a college student but from P.R. China. B has got a high mark in TOEFL test.

- If they meet on a touring trip in China and sit next to the other, their chat will probably be involved in: things of China or things of America?

- If they meet in the same situation in US, will the result be the same?

- In each situation, whose speaking performance might be less satisfactory?

Not surprisingly, all my colleagues assume no matter in China or in America, the topics they choose will be related to China, and B probably has to find a zigzag way to make himself understood. They think although B has got a high mark in TOEFL, he probably still has problem in explaining Chinese specialties for the reason that he has never been exposed to Chinese traditional culture learning inside and outside English classroom.

Actually, effective intercultural communication involves students' awareness of not only the culture of the target language, but also of their own culture, on the basis of which their sensitivity to cultural differences can be built up. However, the education of Chinese students' own culture is neglected in tertiary EFL classroom. The consequence of the neglecting may well account for the fact that many Chinese college students can hardly express their own traditional culture.

Comparatively, Chinese college students are easy to understand what a westerner says about western culture, for they have access to it in their learning process; however, a westerner must have difficulty in understanding Chinese tradition, for it is new to him. Therefore, if a Chinese college student is unable to 
find the specific words or terms to describe their own traditions, the westerners can hardly understand him and their communication is inclined to end with failure.

\section{Reasons for the cultural absence phenomenon}

Looking from both the micro and macro way, I assume that this serious phenomenon might be accounted for from three aspects. In the first place, the present English textbooks seldom include materials introducing Chinese culture. Secondly, Chinese universities pay less attention to providing forum for students to exchange opinions on traditional culture and history; and thirdly, the learning resources in this respect including the web resources are poorly accessible.

Firstly, in Chinese tertiary English teaching environment, intensive reading textbooks usually include texts of narration, argumentation, exposition, and description; listening \& speaking textbooks include topics of greeting, education and some social topics, etc.

The following table indicates the percentage of various styles in both intensive and extensive reading textbook series of College English (Book 1-4), (altogether 160 passages) published by Shanghai Foreign Language Education Press, used by nearly 120,000 undergraduates during the years from 2008 to 2017.

\begin{tabular}{|l|c|c|c|c|}
\hline & narration & argumentation & exposition & description \\
\hline Percentage & $55.4 \%$ & $29.8 \%$ & $10.6 \%$ & $4.2 \%$ \\
\hline
\end{tabular}

These figures mean that the present English textbooks seldom include materials introducing culture of western countries, not to mention the Chinese culture.

Another percentage also shows how inadequately college students are input cultural knowledge in their optional courses not only in English but also in Chinese. At Harbin Institute of Technology (HIT), there are 120 optional courses open for college students, only 33 of them are in the category of humanities, among which there is only 1 course related to culture, and that is A Brief Introduction to $U K$ and USA. The percentage is far less than $1 \%$.

There are over 10 college English textbook series in China, and College English series mentioned above is the most popular one. It can be regarded as a typical one to reveal China's present textbook condition. Generally speaking, most textbooks have some foreign culture input but ignore the input of localized culture (Xie Xiaowan, 2002), that is, Chinese traditional culture. Some teachers are aware of the importance of culture input in teaching, and they introduce some background information of English-speaking countries. However, what they have done is not enough; they omit an important step - comparative study on eastern and western culture. Culture teaching in China should take into consideration the factors of system, comparison and integrity; in this way, language teaching and culture teaching can be combined effectively.

Secondly, college students have no forum to exchange their ideas on Chinese traditional culture and history in English. Although English Corners (a meeting-together activity attended by English fans who talk to one another in English with the purpose of improving English level) are very popular in Chinese colleges, most participants are interested in English learning methods or some topics related to their hobbies. They have no awareness of the importance of talking Chinese culture in English. Since all of them are Chinese, they take it for granted that it is not necessary to talk something familiar to themselves. However, English as a universal tool is used to conduct intercommunication with people of various cultures. Chinese students are supposed to know how to express themselves well about their own culture, otherwise, the intercommunication are likely not to proceed smoothly.

Chinese college students have many places to practice English, such as English clubs and English lectures, but still it is not accessible for them to compare their own traditional culture with that of target language. It is advised that the organizers of English groups take the responsibility to advocate the input of both domestic culture and foreign culture.

Thirdly, the learning resources including web resources are poorly accessible. Internet is playing an important role in Chinese student's English learning, especially for individual learning. However, although the resources on the web are abundant, there is no specific website for Chinese traditional culture learning in English. Take Voice of English as an example, a website for Chinese English-learners. It advocates to giving the equivalent translation to current frequently used Chinese phrases or sentences, for example, there are the translations of Chinese food, new-year greetings, political policies, etc. Nevertheless, it just serves as a reference for English learners; it doesn't organize the information of Chinese traditional culture systemically.

\section{Ways of integrating Chinese traditional culture into tertiary EFL classroom}

At present, Chinese tertiary EFLT focuses on language usages. According to Widdowson [6], teaching language usages cannot guarantee the acquisition of communicative competence, but teaching the use of language can guarantee the mastery of language usages. Therefore, language teaching should shift its focus from language 
formation to language use, so that learners can learn by using and cultivate their communicative abilities [5]. Imputing and comparing both the native culture and that of target language is a good way for English learners to build up their culture awareness and improve their intercultural communication competence.

In view of the reasons of cultural absence mentioned in the preceding part, I hold that we can improve the situation in ways of revising textbooks, giving optional courses related to cultural comparison, and making use of web resources.

\subsection{Revising textbooks}

The contents of intensive reading books and listening books should be involved in "behavior culture" (culture with a small c), while extensive reading books and textbooks of optional courses should be centered on "achievement culture" (culture with a capital C) [8]. Since behavior culture is fit for comparison, social customs, behaviors and notions are good topics to be included in intensive books. Achievement culture, especially arts, literature, music, history, etc, should be introduced in extensive books, because they can be outlined and serve as background knowledge for specific cultural comparison.

The textbook can be organized in topics. Similar topics can be arranged into one unit. For example, in the unit of holidays, New Year's Day, Christmas, Spring Festival, Dragon Boat Festival, Halloween, Thanksgiving Day, and other country's major holidays can be introduced in sections respectively.

\subsection{Providing optional courses}

Giving optional courses in China's tertiary education is also a good way to input Chinese traditional culture [2]. Chinese and Western Cultural Comparison will be an attractive textbook for an optional course in English, if someone is interested in editing it. Other optional courses in English such as Chinese Philosophy Schools and Sightseeing in China will give more direct Chinese culture information for students to communicate with.

\subsection{Making use of web resources}

Making use of resources on the Internet is an alternative for individual learning for cultural acquisition [4]. Learners are not limited by time and place, and they can learn whenever they need for it. However, teachers play a more important role in individual learning. They are guides, organizers and facilitators; they are responsible for organizing systematically so that both learners' language ability and intercultural communication ability can be built up step by step.
The following three paragraphs are the assignments submitted by my students. I asked them to submit passages about the given topics with the help of web resources. If the materials are in Chinese, reorganize them and translate; if they are in English, edit them.

\section{- The Great Wall}

The Great Wall was first built during the Warring states Period (476-421 B.C.). It was a military project built by various small kingdoms for holding back inroads by nomadic tribes coming from the north as well as for protecting against each other. After unifying the six states in 221 B.C., Qin Shihuang, the first emperor of the Qin Dynasty, issued an order that the walls originally built by the State of Qin, Yan and Zhao be linked together and reinforce for defense against the attack by the slaveowner regime in the northern part of China. This is how the well-know, 10,000 li Great Wall came into being. The Great Wall played a significant role in protecting the development of the economy and culture of the central plain area of China.

\section{- Brief Introduction to Chinese Nationalities and Religions}

China is a country of many nationalities and religions. The major religions are Buddhism, Taoism, Islam, and Christianity both Catholic and Protestant, each of which has had a long history here. In China, religion is linked with the history and customs of some of our minority nationalities. For example, for the Huis, Uygurs, and Kazaks, the link is with Islam. For the Tibetans, Mongolians, and Dais, it is with Buddhism (including Tibetan Buddhism or Lamaism); and Catholicism and Protestantism have had a wide influence among the Miaos, Yaos, and Yis.

\section{- Making up a conversation between a Chinese and westerner talking about Chinese specialties.}

(Mr. Brown is discussing with Zhang about the present he is going to buy for his daughter's birthday.)

B: My daughter's birthday is coming. I'd like to buy her a present. What do you suggest? I just want to buy something special.

Z: What about a silk scarf. They're very pretty.

B: Well, she's already had one. I gave her one last year.

Z: Oh, well, why don't you go to the stationer's? They've got some Chinese brushes and inks. 
B: Chinese brushes and inks. Yes, the trouble is that she's not really keen on these things. You know, she can't write with these things.

$\mathrm{Z}$ : Ah, yes, you could try getting embroidery?

B: Embroidery is not a bad idea. But it's rather expensive.

$\mathrm{Z}$ : Yes, true. Well, how about woven bamboo animals and clay sculptures?

B: That's a good idea.

Z: Good. There's a good Arts and Crafts Store in the city center.

B: Good. I'll try there. Thank you for your help.

\section{Conclusion}

Scholars in the field of linguistics and communication have realized the importance of culture input in target language learning. Rivers insists that culture with a small c should be the major content of language teaching, although culture with a capital C should not be neglected. To stress the importance of culture involvement, Hall proposed Ten Primary Message System in 1959, and Taylor \& Sorenson devised Culture Capsules in 1960's [1].

What I want to emphasize in this paper is that the culture input with a small $\mathrm{c}$ and with a capital $\mathrm{C}$ should be carried out not only in target language, but also should be in native language in a comparable way. Through comparison, learners can sense the differences between the mother tongue language and the target language in terms of language structures and cultures, and therefore have a better understanding of both the western culture and eastern culture. In this way, the phenomenon of cultural absence in China's tertiary EFL teaching can be minimized, and English learners will have the basic knowledge to perform intercultural communication significantly.

\section{Acknowledgements}

This paper is sponsored by the research project granted by HIT in 2017- Content-based Tertiary ESP Teaching and Researching with "One Belt One Road" Policy

\section{References}

[1] Chen, S. (2001) Research on Teaching Strategies for Learning Language and Culture $[\mathrm{M}]$, 2001, Beijing: Beijing Language and Culture University Press.

[2] Jing, S.H. (2000) A Practical Program of College Spoken English [M], Beijing: Beijing University Press

[3] Li, X. (2016) 'Analysis of the Phenomenon of Cultural Loss in Japanese Teaching' [J], Journal of Xiangyang Vocational and Technical College, 2016 (3), pp. 100-102.
[4] Nie, A. M (2002) Authenticity in Foreign Language Teaching [A], 2002 EFLT conference.

[5] Shi, W. \& Wu, G. (2016) 'The Cultural Loss and Reconstruction of Teachers' Profession' [J], Teacher Education Research, 2016 (2), pp. 34-39.

[6] Widdowson, H. G. (1999) Teaching Language as Communication $[\mathrm{M}]$, Shanghai: Shanghai Foreign Language Education Press.

[7] Zeiler, T. W. (2018) ‘Globalization' [A], Encyclopedia, https://www.encyclopedia.com/social-sciences-andlaw/economics-business-and-labor/economics-terms-andconcepts/globalization.

[8] Zhang, Z. D. (2000) A Bilingual Course of English Teaching Methodology [M], Beijing: Science Press. 